\title{
GESTÃO DO DESIGN NA PRÁTICA: DISCUSSÃO DOS FATORES HUMANOS E PROCESSUAIS ENVOLVIDOS
}

\section{DESIGN MANAGEMENT IN PRACTICE: DISCUSSION ABOUT HUMAN AND PROCESSUAL FACTORS}

\section{Bruna Ruschel Moreira', Maurício Moreira e Silva Bernardes', Rita Assoreira Almendra ${ }^{2}$}

RESUMO: Com o objetivo de identificar os fatores relacionados com a Gestão do Design (GD) na prática, esta investigação realizou uma pesquisa-ação com cinco companhias brasileiras desenvolvedoras de produtos e atuantes em diferentes segmentos de mercado. Para tanto, foram desenvolvidas 22 atividades que envolveram gestores e colaboradores dessas organizações. As ações foram realizadas através de uma prática integrada em que estavam presentes, ao mesmo tempo, os integrantes das cinco empresas. Ao longo das implementações, foram identificados importantes fatores processuais (descritos como fatores críticos de sucesso, inputs e outputs) e humanos (denominados como vetores positivos, negativos e principais atores) compreendidos como influenciadores do processo de implementação da GD em companhias. Além deles, observaram-se distintos papéis dentre os envolvidos nos níveis estratégico, tático e operacional das companhias e os impactos que eles possuem na dimensão global das organizações. Desta forma, este artigo se propõe a discutir tais resultados e, ao final, busca fazer uma inter-relação entre eles.

PALAVRAS-CHAVE: Gestão do Design; Aplicação Integrada Prática; Empresas.

ABSTRACT: This research aimed to identify factors related to Design Management (DM) in practice, and carried out an action research with five Brazilian companies that make products and are active in different Market segments. We developed 22 activities that involved managers and employees of these organizations, which portrayed an integrated practice that involved all companies at the same time. Along these implementations we identified procedural and behavioral factors that influenced on the implementation of DM. Besides, we observed distinct roles among involved members, and specific impacts that they have on the organization. Thus, this article main propose is to discuss these factors and related all results.

KEYWORDS: Design Management; Practice Integrated Application; Companies.

How to cite this article: MOREIRA, B. R.; BERNARDES, M. M. S.; ALMENDRA, R. A. Gestão do design na prática: discussão dos fatores humanos e processuais envolvidos. Gestão e Tecnologia de Projetos, São Carlos, v. 13, n. 1, p. 59-74. 2018. http://dx.doi.org/10.11606/gtp.v13i1.109576
Fonte de financiamento: Coordenação de Aperfeiçoamento de Pessoal de Nível Superior (Capes), processo no 8005-14-1.

Conflito de interesse: Declaram não haver. Submetido em: 14/01/2016 Aceito em: 16/10/2017 


\section{INTRODUÇÃO}

Muitos pesquisadores internacionais, nas últimas décadas, passaram a dedicar-se à área da Gestão do Design (BORJA DE MOZOTA, 2003; BEST, 2006; BRUCE; COOPER; VAZQUEZ, 1999; DUMAS; MINTZBERG, 1989; GORB, 1990; KOOTSTRA, 2009). No entanto, Libânio e Amaral (2011), a partir de uma revisão sistemática de dissertações brasileiras, verificaram que grande parte desses estudos busca compreender a Gestão do Design (GD) pelas investigações de caráter estritamente teórico. Wolff (2010) concorda que, apesar do farto material disponível, ainda há muitas lacunas que não foram preenchidas.

$\mathrm{Na}$ realidade da indústria, estas carências acirram-se pelo fato de as empresas não terem compreensão aprofundada da importância da inserção do design no nível estratégico para, assim, conseguirem permeá-lo por todas as etapas do desenvolvimento de um produto (LIBÂNIO, 2014). Além disso, há a falta de critérios maduros de prescrições da implantação da GD (WOLFF, 2010) e, também, existe a dificuldade de encontrar pesquisas que se proponham a elaborar modelos mais abrangentes, generalistas e que atinjam setores de maneira mais ampla (LIBÂNIO; AMARAL, 2011).

Portanto, a resistência por parte das empresas em absorver o design de forma estratégica, somada às lacunas das publicações com enfoques práticos da área da GD, é fator que tornam necessários o esclarecimento sobre o assunto e a viabilização de instrumentos capazes de auxiliar na implementação prática do design (MINUZZI; PEREIRA; MERINO, 2003). Diante desse cenário, estão sendo realizadas diferentes ações governamentais, empresariais e de associações, com o objetivo de posicionar a GD como prática mais presente nas empresas brasileiras. Dentre elas, pode-se citar o Projeto ICD - Inovação, competitividade e design, vinculado a um Programa de Pós-Graduação em Design do Sul do país (BERNARDES; OLIVEIRA; VAN DER LINDEN, 2015).

Este artigo é reflexo das evidências coletadas por integrantes deste projeto. Assim, em meio ao processo de pesquisas aplicadas em empresas, o ICD evidenciou a seguinte problemática: como gerir o design de forma integrada em empresas desenvolvedoras de produtos? A fim de buscar responder esse questionamento, o grupo de pesquisa compreendeu ser necessário identificar os fatores relacionados com a aplicação da GD em empresas desenvolvedoras de produtos. Portanto, este artigo tem como objetivo descrever tais fatores a fim de ampliar a discussão acerca das práticas relacionadas com a GD.

Para atender a tal objetivo, foi realizada, primeiramente, uma revisão bibliográfica e, após, uma pesquisa-ação com cinco empresas desenvolvedoras de produtos. As atividades envolveram profissionais dos âmbitos estratégico, tático e operacional das empresas, ao longo de 22 encontros que foram avaliados por meio da observação participante e aplicação de questionários. Os resultados obtidos permitiram concluir que existem fatores humanos e processuais interferindo diretamente na GD das empresas. Assim, o artigo enfoca-se em descrever esses resultados a fim de colaborar com a discussão de pesquisas aplicadas na GD.

\section{GESTÃO DO DESIGN: REVISÃO BIBLIOGRÁFICA SOBRE OS FATORES ENVOLVIDOS NA GD}

Intitula-se como GD a atividade gerencial que situa o design nas empresas em diferentes níveis organizacionais. Esse tipo de gestão visa implementálo como um programa formal de atividades, por meio da comunicação de suas metas corporativas, a fim de coordenar os recursos em todos os níveis e atingir seus objetivos (BORJA DE MOZOTA, 2003). Assim, pode-se compreender que o exercício da GD se coloca como estratégia condutora da visão da empresa e que as habilidades dos designers os situam como importantes atores para que a companhia alcance os fins pretendidos. Essa articulação está relacionada a diversos níveis corporativos, definidos por Borja de Mozota (2003), como estratégico, tático e operacional. 
O nível estratégico associa-se a princípios norteadores da empresa (BORJA DE MOZOTA, 2003), fatores culturais da organização (WOLFF, 2010), capacidade competitiva do organismo (TEIXEIRA; SCHOENARDIE; MERINO, 2011) e recursos financeiros disponíveis (JOZIASSE, 2008), fatores estes administrados com o objetivo de posicionar a empresa de forma estratégica no mercado e de maneira convergente a seus objetivos para, assim, conseguir sustentar a inovação do modelo de negócios, da marca e da sua rede de contatos.

$\mathrm{O}$ nível tático ocupa-se em gerenciar as atividades e os recursos que atendam à estratégia da corporação (BORJA DE MOZOTA, 2003; MARTINS; MERINO, 2011) a fim de desencadear, de forma facilitada, resultados passíveis de ser desenvolvidos pela empresa (TEIXEIRA; SCHOENARDIE; MERINO, 2011). Esse nível acaba por estreitar a relação de coerência com as definições estratégicas e as táticas processuais das atividades do design (PHILLIPS, 2012) a fim de criar um contexto interno favorável ao posicionamento da empresa de forma estratégica no mercado.

Por fim, o nível operacional compreende a realização, execução (JOZIASSE, 2008; WOLFF, 2010) e a operacionalização do lançamento de bens de consumo (produtos ou serviços) que sejam esteticamente atrativos e possuam qualidade e preço coerentes com o posicionamento pretendido pela companhia (GIMENO, 2000). Essas atividades englobam diferentes formas de articulação entre setores e é o nível mais encontrado nas empresas em função de ser responsável pela execução do projeto em si (CABRAL, 2008).

Por todas as características expostas, percebe-se que a compreensão dos benefícios e metas do design, em todos os níveis da estrutura de uma corporação, coloca-se como fundamental para o gerenciamento em função de envolver diversos fatores. A fim de fomentar a discussão teórica acerca de tais fatores, a revisão bibliográfica enfoca-se em duas vertentes: primeiramente busca compreender quais os fatores apontados em três modelos existentes da GD; na sequência, faz-se uma discussão acerca da presença de fatores que, possivelmente, podem estar relacionados com a aplicabilidade da GD em empresas.

\section{Fatores apontados em modelos da GD}

Os modelos escolhidos foram definidos com base nos seguintes critérios: a) menção dos componentes (atores, elementos, processos, fase, entre outros) relacionados à GD em uma empresa; b) apresentação de fatores tangíveis e intangíveis referentes à aplicação e manutenção da GD em uma companhia. Assim, conforme pode ser observado a seguir, cada modelo analisado contempla um ou mais critérios estabelecidos.

Earl Powell (1998), ex-presidente do Design Management Institute (DMI), indicou seis categorias de conhecimentos, habilidades e atitudes que se constituem elementos essenciais para o sucesso da GD: a) propósito: para ser externado ao mercado e aos seus colaboradores; b) pessoas: são as estruturas das empresas e suas ações e atitudes que determinam o futuro da corporação; c) presença: há uma necessidade humana fundamental para a estabilidade, consistência e significado e, logo, as organizações são mais eficazes quando essas características estão presentes entre colaboradores; d) processo: o processo de mudança de uma empresa para o mercado é complexo e exige reflexão e experiência de seus participantes, e o design é uma disciplina que pode auxiliar, uma vez que tem a ideia do desenvolvimento no cerne de sua educação e prática; e) projetos: gerenciar ou trabalhar em uma equipe de projeto amplia a percepção sobre as normas e os valores das organizações; f) prática: corresponde à prática de design através das operações do dia a dia, do planejamento de desempenho e do desenvolvimento de RH.

Como pode-se observar os elementos "propósito", "presença” e "pessoas" situam-se como fatores intangíveis e relacionam-se às intenções da empresa; enquanto "processo", "projetos" e "prática" se tangibilizam de diferentes formas para desenvolver tais intenções. Assim, é possível compreender 
que Powell (1998) articula tais fatores com os níveis estratégico (propósito e presença), tático (projetos e processos) e operacional (prática).

Já Martins (2004) desenvolveu um modelo intitulado Disco integrador da Gestão do Design, que é um aperfeiçoamento da Roda de Porter, no qual o cliente interno (funcionário) está no centro do disco (diferente de Porter que coloca o usuário no centro) e relaciona-se às ações integradas entre as unidades organizacionais da empresa. Desta forma, fatores internos incidem sobre a atuação do design nos setores da companhia que percebem e incorporam sua imagem em um movimento que corrobora a transmissão da percepção positiva do cliente externo.

Segundo a autora, há também diferentes fatores externos que influenciam a atuação do design nos setores da organização: economia (geral e do setor), ambiente sociocultural, ambiente demográfico, concorrentes, fornecedores, setor de atuação, tendências, expectativas da sociedade, meio ambiente e política governamental. Diante disso, verificase que o design circunda a organização (setores e funcionários) e se coloca como elemento integrador entre a empresa e os clientes externo e interno.

Enfim, Wolff(2010) elaborou um modelo conceitual apontando os diferentes fatores relacionadas a ela. Segundo a autora, a GD está correlacionada a três dimensões principais (processo, competência e estratégia) que estão interligadas a dois fatores: estruturas (questões conectadas a cada uma das dimensões de design enquanto gestão) e entendimentos (compreensão das pessoas envolvidas sobre sua própria realidade).

A dimensão "Processo" envolve a infraestrutura da empresa e diz respeito às relações existentes entre as equipes e a forma como o design está integrado a outras áreas. Já a dimensão "Competência" vincula-se com a equipe e suas formas de fazer e compreender design. Por fim, a dimensão "Estratégia" está ligada aos controles estratégicos relacionados ao design disponibilizado e utilizado e aos quais as equipes estão subordinadas.

\section{Discussão dos fatores relacionados à Gestão do Design}

Conforme se observa no Quadro 1, todos os modelos citam, de uma forma ou de outra, fatores relacionados à prática da GD em empresas. Powell (1998) busca enfocar-se nos conhecimentos, habilidades e atitudes que, ora intangíveis, ora tangíveis, somam-se com o objetivo de alavancar a GD em uma companhia. Já Martins (2004) realiza o cruzamento das relações estabelecidas entre o design, os clientes internos (funcionário) e externos (consumidor, usuário). Finalmente Wolff (2010) enfatiza a importância que os processos, a competência e a estratégia possuem na GD.

O quadro analítico também permite concluir que cada modelo possui um recurso central que reúne as atividades e ações da GD. Powell (1998) afirma que esse recurso se caracteriza como um conjunto de seis tipos de conhecimentos, habilidades e atitudes; já Martins (2004) defende que a centralidade está no cliente interno e Wolff (2010) compreende as estruturas e os entendimentos.

Quadro 1: Discussão das propostas analisadas

\begin{tabular}{|l|l|l|l|}
\hline \multirow{2}{*}{$\begin{array}{l}\text { Perguntas sobre os modelos } \\
\text { analisados }\end{array}$} & \multicolumn{3}{|c|}{ Autores dos modelos analisados } \\
\cline { 2 - 4 } & Powell (1998) & Martins (2004) & Wolff (2010) \\
\hline $\begin{array}{l}\text { Há clareza nos elementos constituintes } \\
\text { para a aplicação da GD? }\end{array}$ & $\begin{array}{l}\text { Sim, são: pessoas, prática, } \\
\text { propósito, projeto, presença e } \\
\text { processo. }\end{array}$ & $\begin{array}{l}\text { Sim, são: cliente interno, } \\
\text { cliente externo, variáveis } \\
\text { externas e variáveis internas. }\end{array}$ & $\begin{array}{l}\text { Sim, são: processo, } \\
\text { competência e } \\
\text { estratégia. }\end{array}$ \\
\hline $\begin{array}{l}\text { Qual(is) são o(s) fatores centrais² da } \\
\text { proposta? }\end{array}$ & $\begin{array}{l}\text { Conjunto de conhecimentos, } \\
\text { habilidades e atitudes. }\end{array}$ & Cliente interno (funcionário). & $\begin{array}{l}\text { Estruturas e } \\
\text { entendimentos. }\end{array}$ \\
\hline
\end{tabular}

Fonte: Elaborado pelos autores 
Dessa forma, observa-se que os fatores relacionados à GD e encontrados na literatura apontam elementos tangíveis e, sobretudo, intangíveis. Os tangíveis centralizam-se em fatores relacionados com as pessoas, o projeto e as estruturas; já os intangíveis vinculam-se a prática, processo, propósito, presença, conhecimentos, habilidades, atitudes, entendimento, competência e estratégia.

\section{Fatores relacionados à aplicabilidade da GD}

Ao realizar uma revisão bibliográfica acerca de possíveis fatores relacionados à aplicabilidade da GD, foi possível apontar, pelo menos, cinco categorias distintas.

a) Fatores relacionados à abrangência de atuação: a GD possui fronteiras pouco nítidas com outras áreas corporativas e, na maioria das vezes, sobrepõe-se a outras disciplinas devido à amplitude de atuação (WALTON, 2000). Além disso, não trata apenas de um processo de mudança para dar forma a determinado negócio, mas também filiase a um entendimento que visa a uma mudança da visão corporativa da empresa (BORJA DE MOZOTA, 2003). Por isso, o maior desafio da aplicação prática da GD reside em gerar impactos positivo e holístico sobre todos os contextos, disciplinas, funções, relações e conexões das empresas (BEST, 2006). Assim, a grande dimensão/dispersão da área pode ser um dos fatores que dificultam a operacionalização de modelos sistemáticos de implementação da GD.

b) Fatores relacionados à multiplicidade de setores, cargos e formações envolvidos: o design associa-se à alocação de recursos, sobretudo com o estímulo das pessoas envolvidas em um projeto (GIRARDI; ROBIN, 2006). Além disso, parte significativa do desenvolvimento de um projeto ou das decisões, que influenciam o processo de design, não é feita por designers, mas sim, por outras pessoas na organização (HALES, 1987) chamadas de silent designers - profissionais que não são designers, mas possuem impacto significativo sobre o resultado do projeto, mesmo sem ter consciência disso (GORB; DUMAS 1987). Nesse sentido, mapear os principais atores envolvidos, identificando como eles podem fornecer valor à aplicabilidade da GD nas empresas, caracteriza-se como fator vinculado à dificuldade de aplicação prática da área.

c) Fatores relacionados a paradigmas da gestão: os gestores possuem papel importante na aplicação da GD, uma vez que coordenam os princípios da empresa e gerenciam o espaço do design nela. Para tanto, faz-se necessário que saibam quebrar paradigmas, flexibilizar-se e adotar formas de gestão menos tradicionais para ceder espaço a uma gestão orientada pelo design. Sem direção e encorajamento claros dos gestores, as atividades podem perder o senso de importância, atenção e compromisso dos funcionários (VOM STAMM, 2008). Contudo, a aprendizagem do design pode se estabelecer como paradigma para os gestores, uma vez que trata da incerteza, o que, antagonicamente, se demonstra pelo fato de que os gestores foram, historicamente, treinados para evitar riscos (LIEDTKA; ROSEN; WILTBANK, 2009). Por isso, todos esses fatores colocam-se frente aos desafios da GD em muitas empresas, graças ao seu caráter disruptivo em termos de gestão que, frequentemente, está mediado pela incerteza intrínseca ao cenário atual do mercado.

d) Fatores relacionados à amplitude da utilização do design: não existe uma única forma de se utilizar design ou um único papel para o designer no ambiente corporativo. As empresas o utilizam com diferentes intenções (seja para atribuir valor estético, ou para posicionar uma empresa com vantagens competitivas) e todas são 
legítimas (WOLFF, 2010). Portanto, a amplitude do fazer design e, consequentemente, da GD maximiza os desafios inerentes a esse tipo de gestão, em função de envolver muitas formas de aplicar o design.

e) Fatores relacionados à intangibilidade dos benefícios do design: design é um processo que envolve muitas pessoas e coisas. Quando o resultado do processo de design é tangível, como o que se percebe com artefatos, é relativamente simples evidenciar sua contribuição. No entanto, quando os extratos da atividade são intangíveis, por exemplo alterações nos comportamentos de uma organização e cultura, a contribuição do projeto é muito menos clara e, logo tornase difícil de ser estruturada (JOHNSON; McHATTIE, 2014). Assim, a compreensão da dimensão do design erige-se como importante fator relacionado à aplicação do gerenciamento orientado pelo design, pois seu desconhecimento pode levar barreiras ao processo de design (WOLFF, 2010).

\section{PROCEDIMENTOS METODOLÓGICOS}

As evidências descritas neste artigo são resultado da revisão bibliográfica, brevemente apresentada no item anterior, e, sobretudo, da pesquisa-ação realizada com cinco empresas que, neste estudo, foram denominadas como A, B, C, D e E, por motivos de sigilo de pesquisa. Conforme já mencionado, foram desenvolvidas 22 ações que somaram 78 horas de práticas envolvendo os colaboradores dos níveis estratégico, tático e operacional das companhias.

Todas as atividades foram previamente validadas pelos gestores das empresas envolvidas e, somente a partir disto, desenvolvidas nas organizações (Quadro 2).

Quadro 2: Empresas participantes da pesquisa-ação

\begin{tabular}{|l|l|l|l|c|}
\hline & $\begin{array}{c}\text { Tempo de } \\
\text { existência }\end{array}$ & \multicolumn{1}{|c|}{$\begin{array}{c}\text { Segmento de } \\
\text { atuação }\end{array}$} & $\begin{array}{c}\text { Produtos } \\
\text { desenvolvidos }\end{array}$ & $\begin{array}{c}\text { Número de } \\
\text { funcionários }\end{array}$ \\
\hline Empresa A & 48 anos & $\begin{array}{l}\text { Ferramentas e } \\
\text { acessórios para } \\
\text { pintura }\end{array}$ & $\begin{array}{l}\text { Pincéis, trinchas, rolos } \\
\text { etc. }\end{array}$ & 729 \\
\hline Empresa B & 67 anos & $\begin{array}{l}\text { Utensílios de limpeza } \\
\text { doméstica }\end{array}$ & $\begin{array}{l}\text { Vassouras, esponjas, } \\
\text { escovas etc. }\end{array}$ & 957 \\
\hline Empresa C & 45 anos & $\begin{array}{l}\text { Utilidades domésticas } \\
\text { e organizadores }\end{array}$ & $\begin{array}{l}\text { Potes, organizadores, } \\
\text { lixeiras etc. }\end{array}$ & 684 \\
\hline Empresa D & 67 anos & Brinquedos & $\begin{array}{l}\text { Playgrounds, jogos de } \\
\text { tabuleiro, triciclos etc. }\end{array}$ & 525 \\
\hline Empresa E & 59 anos & Calçados & $\begin{array}{l}\text { Sapatilhas, botas, } \\
\text { scarpins, chinelos etc. }\end{array}$ & 4.000 \\
\hline
\end{tabular}

Fonte: Elaborado pelos autores

Como se observa no Quadro 2, as empresas envolvidas possuem significativa experiência de mercado (entre 48 e 67 anos), são de grande porte (entre 525 e 4.000 funcionários) e atuam em segmentos variados (ferramentas profissionais, brinquedos, calçados, utilidades domésticas e de limpeza).

As ações foram realizadas de forma conjunta com representantes das empresas e alguns de seus colaboradores e visaram atingir os níveis estratégicos (atividades com os gestores), táticos e operacionais (atividades com os colaboradores) das companhias. Conforme se observa no Quadro 3, as intervenções do nível estratégico foram estruturadas em cinco reuniões direcionadas aos $\mathrm{CEO}^{3}$, somando 10 horas de atividades. Esses encontros foram mediados por professores visitantes da Universidade de Lisboa, Delft University of Technology, Illinois Institute of Technology, University of California, Berkeley e Universidad de Zaragoza. Essas instituições

\footnotetext{
Chief Executive Officer.
} 
tiveram como objetivo discutir alguns aspectos relacionados à GD como: inovação versus design; aquisição de conhecimento conjunto em ambientes organizacionais; valor do design para a empresa e multiplicidade do design.

Quadro 3: Ações desenvolvidas na pesquisa-ação

\begin{tabular}{|l|l|l|l|}
\hline Nível & \multicolumn{1}{|c|}{$\begin{array}{c}\text { Ações } \\
\text { desenvolvidas }\end{array}$} & Objetos de estudo & Tempo investido \\
\hline $\begin{array}{l}\text { Implementações de } \\
\text { atividades no nível } \\
\text { estratégico }\end{array}$ & $\begin{array}{l}5 \text { reuniões de } \\
\text { sensibilização }\end{array}$ & $\begin{array}{l}\text { CEO das empresas } \\
\text { A, B, C, D e E. }\end{array}$ & $10 \mathrm{~h}$ \\
\hline $\begin{array}{l}\text { Implementaç̃os de } \\
\text { atividades no nível tático }\end{array}$ & 3 workshops & $\begin{array}{l}\text { Colaboradores do } \\
\text { marketing, design, } \\
\text { engenharia, } \\
\text { comercial e vendas } \\
\text { das empresas A, B, }\end{array}$ & $12 \mathrm{~h}$ \\
\cline { 1 - 2 } $\begin{array}{l}\text { Implementações de } \\
\text { atividades no nível } \\
\text { operacional }\end{array}$ & 14 workshops & & \\
\hline
\end{tabular}

Fonte: Elaborado pelos autores.

Igualmente importante, realizou-se a implementação nos níveis tático (3 atividades) e operacional (14 atividades) com foco nos colaboradores, somando 78 horas ao total. As atividades do nível tático visaram compreender inputs e outputs (entradas e saídas) relacionados ao processo de desenvolvimento de produto, além dos respectivos pontos críticos associados àqueles. Para realização de tais atividades, os colaboradores mapearam todas as etapas e os setores envolvidos no processo de desenvolvimento de produto das empresas. Além disso, utilizaram este mapeamento para discutir os pontos mais críticos do processo a fim de compreender como e quais setores estavam envolvidos.

Ademais, elas focaram em fomentar a troca de boas práticas desenvolvidas pelas empresas participantes do estudo. Para isso, foram elencados os pontos críticos mencionados na atividade anterior a fim de utilizá-los como tópicos de discussão entre as empresas. Assim, as companhias buscaram apontar boas práticas relacionadas a problemas mencionados por outras empresas presentes na pesquisa-ação, o que estimulou os colaboradores a aprender com experiências positivas desenvolvidas por outras pessoas e/ou empresas.

Já as atividades relacionadas ao nível operacional voltaram-se para a discussão e utilização de ferramentas de projetos com foco no desenvolvimento de resultados inovadores. Para isso, utilizou-se a obra 101 Design Methods (2012), escrita por Vijay Kumar, que sugere o processo projetual marcado por sete etapas: Sense Intent, Know Context, Know People, Frame Insights, Explore Concepts, Frame Solutions e Realize Offering. Segundo Kumar (2012), essas etapas não ocorrem, necessariamente, de forma linear e, por isso, não têm uma ordenação fixa de realização das etapas. $\mathrm{O}$ modelo permite voltar a qualquer momento para fases anteriores e determinar a ordenação das etapas do projeto de acordo com a necessidade do projetista.

Tal obra foi escolhida em virtude de estruturar-se por meio de ferramentas projetuais testadas em empresas. Além de ilustrar esses casos, Kumar (2012) também aponta os benefícios da utilização de cada ferramenta e menciona quais resultados elas podem fornecer.

\section{Número de colaboradores e gestores participantes da pesquisa-ação}

O número de participantes de cada companhia variou de acordo com cada ação proposta. Todos os colaboradores vinculados a essas atividades foram definidos pelas próprias empresas que os escolheram de acordo com o conteúdo abordado nas ações. No entanto, houve o incentivo para que o maior número de departamentos participasse (Quadro 4). 
Quadro 4: Número de participantes das empresas em cada atividade

\begin{tabular}{|c|c|c|c|c|c|c|}
\hline $\begin{array}{l}\text { Atividade } \\
\text { número }\end{array}$ & Enfoque & Empresa A & Empresa B & Empresa C & Empresa D & Empresa E \\
\hline 1 & Gestores & 2 & 1 & 1 & 1 & 3 \\
\hline 2 & Gestores & 2 & 1 & 1 & 1 & 3 \\
\hline 3 & Gestores & 1 & - & - & -- & 2 \\
\hline 4 & Gestores & 1 & - & - & - & 1 \\
\hline 5 & Gestores & 2 & 1 & 1 & - & 1 \\
\hline 6 & Colaboradores & 10 & 14 & 11 & 4 & 5 \\
\hline 7 & Colaboradores & 9 & 14 & 8 & 4 & 5 \\
\hline 8 & Colaboradores & 10 & 14 & 11 & 4 & 5 \\
\hline 9 & Colaboradores & 10 & 14 & 11 & 4 & 5 \\
\hline 10 & Colaboradores & 7 & 5 & 8 & 3 & 5 \\
\hline 11 & Colaboradores & 7 & 5 & 8 & 3 & 5 \\
\hline 12 & Colaboradores & 8 & 7 & 4 & 3 & 5 \\
\hline 13 & Colaboradores & 8 & 7 & 4 & 3 & 5 \\
\hline 14 & Colaboradores & 7 & 8 & 4 & 3 & 5 \\
\hline 15 & Colaboradores & 5 & 7 & 4 & 3 & 5 \\
\hline 16 & Colaboradores & 5 & 7 & 4 & 3 & 5 \\
\hline 17 & Colaboradores & 7 & 9 & 4 & 3 & 5 \\
\hline 18 & Colaboradores & 7 & 8 & 4 & 3 & 5 \\
\hline 19 & Colaboradores & 4 & 7 & 4 & - & 5 \\
\hline 20 & Colaboradores & 6 & 5 & 3 & - & 5 \\
\hline 21 & Colaboradores & 6 & 5 & 3 & 2 & 5 \\
\hline 22 & $\begin{array}{l}\text { Colaboradores } \\
\text { e gestores }\end{array}$ & 7 & 9 & 3 & 4 & 6 \\
\hline
\end{tabular}

Fonte: Elaborado pelos autores.

O Quadro 4 aponta que as empresas A e E sempre envolveram gestores nas atividades do nível estratégico, diferente de B, C e D. Já as práticas relacionadas aos níveis tático e operacional obtiveram presença constante dos colaboradores de todas as companhias.

\section{Formas de análise da pesquisa-ação}

As atividades realizadas ao longo da pesquisa-ação foram analisadas a fim de facilitar a identificação dos fatores relativos ao processo de GD nas empresas. Tais avaliações foram embasadas na: a) observação participante do comportamento dos gestores e colaboradores, realizada pelos autores deste artigo; b) análise de questionários aplicados durante as atividades implementadas nos níveis tático e operacional.

A observação participante aconteceu na implementação de todos os estágios da pesquisa-ação e, por isso, as atividades foram registradas em atas que sintetizaram seus fluxos (tempo e objetivos de cada uma delas); os comentários mencionados pelos gestores e colaboradores e o comportamento dos integrantes ao longo do processo de implementação de ações. Tais informações foram, posteriormente, analisadas e compiladas por grupos de similaridades que são mencionados no item a seguir.

$\mathrm{O}$ questionário ${ }^{4}$ foi aplicado em todas as atividades dos níveis tático e operacional e teve como objetivo coletar as percepções com relação aos registros de lições aprendidas e verificar as sugestões e comentários que pudessem colaborar com o desenvolvimento das atividades da pesquisa-ação.

$4 \quad$ O questionário é composto por três questões: (1) atividade realizada; (2) data de realização da atividade; (3) registro de lições aprendidas com a atividade. 


\section{GESTÃO DO DESIGN: RESULTADOS DA PESQUISA-AÇÃO}

Com a implementação da pesquisa-ação, foi possível observar a presença de fatores humanos e processuais, presentes em todos os âmbitos da GD (estratégico, tático e operacional). Dentre eles, foram identificados:

a) Fatores humanos que, neste estudo, são descritos enquanto vetores positivos (VP), vetores negativos (VN), vetores neutros (VNT) e principais atores (PA);

b) Fatores processuais, denominados nesta pesquisa como fatores críticos de sucesso (FCS ${ }^{5}$ ), inputs (IN) e outputs (OU).

Como se observa (Figura 1), ambos os grupos de fatores, tanto humanos quanto processuais, se relacionam a diversos níveis estruturais da empresa e caracterizam-se, sobretudo, por ser intangíveis. Ou seja, não se incorporam a tangibilidade de maquinários e/ou produtos.

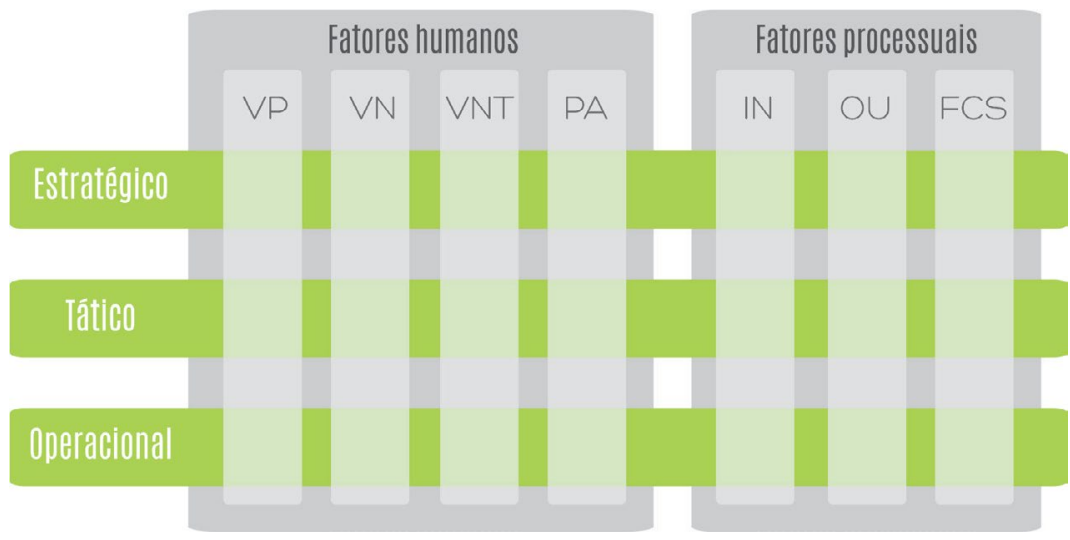

Os vetores positivos, negativos e principais atores foram identificados por meio de duas formas: pelos comentários dos gestores e pelas atitudes dos colaboradores. Os comentários dos gestores, registrados nas observações realizadas nas reuniões do nível estratégico, evidenciaram que existem colaboradores que se posicionam como "entraves" (grifo dos gestores) e/ou "entusiasmados" (grifo dos gestores) ao longo dos processos da empresa. Além disso, os gestores mencionaram que geralmente há, na maioria das áreas, pessoas que "tomam para si" (grifo dos gestores) algumas atividades, fato que as caracterizam como importantes atores em seus setores e, até, na empresa.

As atitudes dos colaboradores reforçaram, de certa forma, os relatos dos gestores. Ao longo das atividades nos níveis táticos e operacional, foi possível observar a presença de funcionários altamente motivados, assim como aqueles com participação e entusiasmo pouco significativos. Além disso, alguns mostraram-se com papéis de liderança ao longo das atividades.

Já os FCS, inputs e outputs foram identificados por meio dos resultados obtidos com a observação das atividades realizadas nos níveis táticos e operacionais e, também, pela análise dos resultados obtidos com os questionários. A partir dessas evidências, foi possível agrupar informações relativas aos processos de desenvolvimento de produtos e, sobretudo, seus pontos críticos. Assim, tais informações foram agrupadas por similaridades que, neste estudo, são denominadas FCS de comunicação, conhecimento, projetos, recursos humanos e estratégia.

A fim de ampliar a discussão acerca de tais resultados, todas as evidências são discutidas a seguir.
Figura 1: Fatores presentes nos âmbitos da Gestão do Design

Fonte: Desenvolvido pelos autores 


\section{Fatores humanos}

O processo de implementação das ações permitiu identificar alguns VP nas empresas. Compreendeu-se como VP, neste estudo, aqueles colaboradores que entendem todos os níveis de atuação do design (ou grande parte deles) e sua importância para a competitividade da empresa e, por isso, o disseminam a fim de que sua aplicação prática seja bemsucedida. A presença deles é capaz de contagiar positivamente o ambiente que os cercam e, assim, envolver os demais colaboradores na busca pela aplicação integral do design na empresa. Geralmente, esses vetores são caracterizados pela motivação intrínseca que os faz utilizar o design na corporação de forma ampla, sistêmica e coerente. Também manifestam-se, sempre, de forma disposta a aprender algo novo e se preocupam em utilizálo em diferentes operações na empresa.

Os VP relacionados ao nível estratégico representam os gestores que compreendem a importância da pesquisa e do desenvolvimento da empresa e percebem que estas ações se caracterizam como investimentos essenciais à corporação e não como gastos dispensáveis. Já os vetores referentes ao nível tático se configuram como colaboradores que possuem o enfoque voltado ao mercado a fim de observar os comportamentos culturais e sociais que influenciam o desenvolvimento dos produtos e serviços. Para tanto, normalmente se utilizam de ferramentas apropriadas para geração, identificação e seleção de ideias. Para eles, faz-se necessário entregar valor para o usuário a fim de que ele posicione a empresa de forma mais competitiva se comparada às concorrentes. E os vetores situados no âmbito operacional se caracterizam por aceitar desafios no processo de prototipagem, compreendendo que novos produtos garantem a continuidade das futuras produções em série da fábrica. Além de colaborar com protótipos novos, eles normalmente participam da busca por materiais, processos e acabamentos que estejam de acordo com o pretendido nos novos projetos.

Por tudo, identificou-se que quanto mais alta a posição hierárquica do VP, maior será o impacto sob os demais colaboradores e setores. Assim, podese concluir que vetores positivos situados na alta gestão podem facilitar, de forma significativa e integrada, o processo de GD na empresa.

No entanto, as evidências coletadas na pesquisa-ação também apontaram a presença de VN. Os VN são colaboradores que possuem comportamentos opostos aos VP. Eles não compreendem na totalidade os níveis de atuação do Design e sua importância para a competitividade da empresa. Dessa forma, não o disseminam dentro da corporação e, às vezes, colocam-se como principais entraves para que sua aplicação prática seja bem-sucedida. Além disso, a presença destas pessoas pode contaminar negativamente o ambiente em que estão inseridas, incluindo demais colaboradores e setores. Frequentemente, são caracterizados pela descrença da utilização estratégica do design e, por isso, não o utilizam, ou utilizam de forma parcial, ou apenas para questões operacionais. Além disso, caracterizam-se pela pouca vontade de aprender novas formas de propor mudanças e embasam-se, comumente, em modelos processuais, metodológicos e gerenciais tradicionais.

Os VN identificados na alta gestão, frequentemente, valem-se da ideia de que "não se mexe em time que está ganhando" e "sempre fizemos assim e continuaremos fazendo porque no passado deu certo". Eles se comportam de forma reativa às novas propostas apresentando, constantemente, descrença por associar o novo à incerteza. Os vetores negativos inseridos nos níveis táticos se configuram como colaboradores que possuem o enfoque mais voltado para as disponibilidades da fábrica do que para as oportunidades inseridas no mercado. Fazem pesquisas, mas com o objetivo de identificar as reações dos concorrentes e não de analisar os sinais emitidos pelos consumidores. Normalmente, utilizam-se de ferramentas mais tradicionais de análise de mercado e, portanto, compreendem que a projeção de significados para o usuário se relaciona apenas a empresas específicas, como Google, Disney, Nike etc., e não pode ser implementada 
em todos os setores. E os vetores negativos operacionais classificam-se como colaboradores que compreendem novos desafios de prototipagem como "atraso" para a produção. Por isso, normalmente, não colaboram no processo produtivo e teste do algo novo, inserindo muitos empecilhos ao longo da prática.

Assim, também se identificou que quanto mais alta a posição do vetor negativo, maior o sentimento de descrença na empresa perante os colaborardes. A falta de crença, por sua vez, pode acarretar comportamentos disfuncionais, como a pouca vontade de propor o novo, o baixo estímulo aos desafios e atitudes mais reativas do que proativas.

Além dos VP e dos VN, também se evidenciou a presença de vetores neutros (VNT), que não se caracterizam por vetores positivos ou negativos, mas, sobretudo, estão suscetíveis a influência destes. Assim, pode-se dizer que, quando bem-influenciados, podem se tornar aliados na GD em empresas. Caso contrário, também podem personificar entraves nas organizações devido à contaminação oriunda dos VN.

Além de vetores, foram identificados outros fatores humanos como principais atores (PA), que se caracterizam pelos funcionários e/ou gestores identificados com poderes decisórios nas empresas e, assim, munidos de capacidades de persuasão nos níveis em que estão inseridos. Logo, podem existir PA com vertentes de vetores positivos ou negativos.

Os PA envolvidos com a gestão do nível estratégico caracterizam-se por CEO, gerentes administrativos, gerentes estratégicos, gerentes financeiros, gerentes de marketing e gerentes de design. Já no nível tático, eles podem ser gerentes de recursos humanos, de design, de marketing e de produção. E, por fim, os do nível operacional relacionam-se aos gestores de design, de marketing, de produção (em todas as suas derivações), do comercial e das vendas.

\section{Fatores processuais}

As análises também permitiram identificar a presença de fatores processuais na implementação da GD em empresas. Dentre eles, alguns FCS apresentaram significativa relação com a inserção do design na corporação. Estes foram subdivididos em cinco grupos: comunicação, conhecimento, projetos, recursos humanos e estratégia. Para tanto, indica-se, a seguir, as ações necessárias para combatê-los.

a) FCS relacionados à comunicação: treinamento dos colaboradores de diferentes setores para compreensão de seus papéis no processo organizacional de desenvolvimento do produto; sistematização do fluxo de informação para manter a continuidade dos processos inerentes às empresas; utilização de cronograma de projeto formalizado e socializado entre todos os setores da companhia; sistematização das formas de explicitação de problemas para facilitar a identificação de gargalos existentes no processo e formalização dos processos projetuais.

b) FCS relacionados ao conhecimento: capacitação dos colaboradores de diferentes níveis hierárquicos da empresa com a mesma base teórica acerca de design; foco no planejamento estratégico da empresa para a criação de mecanismos estruturados com o objetivo de colocálo em prática; organização de banco de dados com informações que possam ser acessadas e compartilhadas por todos os setores da empresa e organização de programas de incentivo à inovação e utilização integrada do design.

c) FCS relacionados a projetos: utilização de ferramentas de projetos que visam fomentar a inovação em diferentes tipos e realização de retroalimentação entre o setor comercial e os setores envolvidos na estratégia do desenvolvimento de novos produtos. 
d) FCS relacionados a Recursos Humanos: construção e explicitação de um plano de carreira claro e correlacionado com o incentivo à inovação e ao uso integrado do design e estruturação de um programa formal de investimento na ampliação do conhecimento dos colaboradores.

e) FCS relacionados à estratégia da empresa: fixação de valor investido em design como investimento aplicado no ativo da companhia; desenvolvimento de um programa de metas embasando-se no planejamento estratégico da organização; compreensão das vantagens financeiras que podem ser obtidas pela gestão integrada do design e realização de uma orientação estratégica guiada por oportunidades percebidas no mercado e não apenas pela disponibilidade fabril.

Dessa forma, acredita-se que quando os FCS das empresas não estão articulados, podem fortalecer alguns fatores nocivos à prática da GD. Conforme se observa no Quadro 5, a falta de conhecimento na área do design está relacionada à subutilização das práticas do designer e o pouco espaço que ele possui em muitas empresas. Além disso, pode acarretar a inexistência de fatores de mensuração de resultados do design. A pouca abertura para as novas ideias, somada a modelos de gestão mais tradicionais, também pode resultar em respostas mais reativas do que proativas; além de investimentos, sobretudo, tecnológicos em detrimento dos intelectuais.

Além disso, também foram identificados alguns fatores processuais relacionados aos inputs e aos outputs mais significativos para a aplicação da GD nas empresas. Esses elementos foram identificados de forma encadeada entre si, em que cada nível depende, direta ou indiretamente, dos outros como uma espécie de engrenagem.

Quadro 5: Fatores nocivos para a Gestão do Design na prática

\begin{tabular}{|c|c|c|c|}
\hline \multicolumn{4}{|c|}{ Fatores nocivos à Gestão do Design: relação causa e efeito } \\
\hline \multirow{2}{*}{ Causa } & \multicolumn{3}{|c|}{ Efeitos } \\
\hline & Nível estratégico & Nível tático & Nível operacional \\
\hline \multirow{4}{*}{$\begin{array}{l}\text { Falta de } \\
\text { conhecimento } \\
\text { da alta gestão } \\
\text { sobre o design e } \\
\text { seus benefícios }\end{array}$} & $\begin{array}{l}\text { Pouco investimento e espaço } \\
\text { para a área do design na } \\
\text { empresa. }\end{array}$ & $\begin{array}{l}\text { Pouca articulação e } \\
\text { conhecimento dos outros setores } \\
\text { da empresa com relação ao } \\
\text { design. }\end{array}$ & $\begin{array}{l}\text { Acúmulo de atividades do design } \\
\text { operacional e, assim, subutilização } \\
\text { das competências dos profissionais } \\
\text { da área. }\end{array}$ \\
\hline & $\begin{array}{l}\text { Desconhecimento de métodos } \\
\text { de mensuração do design na } \\
\text { empresa. }\end{array}$ & $\begin{array}{l}\text { Enfase nos processos tangíveis } \\
\text { em detrimento dos intangíveis. }\end{array}$ & Ênfase na mensuração das vendas. \\
\hline & $\begin{array}{l}\text { Planejamento estratégico } \\
\text { desalinhado com o design. }\end{array}$ & \multirow{2}{*}{$\begin{array}{l}\text { Ênfase nos processos mais } \\
\text { tradicionais de relação com o } \\
\text { mercado. }\end{array}$} & \multirow{2}{*}{$\begin{array}{l}\text { Enfase projetual nos aspectos mais } \\
\text { quantitativos que qualitativos dos } \\
\text { produtos. }\end{array}$} \\
\hline & Metas de curto prazo. & & \\
\hline \multicolumn{4}{|c|}{ Fatores nocivos à Gestão do Design: relação causa e efeito } \\
\hline \multirow{2}{*}{ Causa } & \multicolumn{3}{|c|}{ Efeitos } \\
\hline & Nível estratégico & Nível tático & Nível operacional \\
\hline \multirow{2}{*}{$\begin{array}{l}\text { Pouca abertura } \\
\text { para novas } \\
\text { ideias /Modelos } \\
\text { de gestão mais } \\
\text { tradicionais }\end{array}$} & $\begin{array}{l}\text { Reações mais reativas que } \\
\text { proativas com relação às } \\
\text { oportunidades de novas } \\
\text { aberturas para o design. }\end{array}$ & $\begin{array}{l}\text { Enfase na articulação dos } \\
\text { processos mais produtivos do } \\
\text { que analíticos de mercado e } \\
\text { consumidor. }\end{array}$ & $\begin{array}{l}\text { Desenvolvimento de produtos } \\
\text { menos assertivos no mercado } \\
\text { e menos relacionados às } \\
\text { expectativas/necessidades dos } \\
\text { consumidores. }\end{array}$ \\
\hline & $\begin{array}{l}\text { Investimento prioritário no } \\
\text { capital tecnológico da empresa } \\
\text { em detrimento do intelectual. }\end{array}$ & $\begin{array}{l}\text { Recursos focados mais na } \\
\text { compra de maquinários do que } \\
\text { em cursos de atualização. }\end{array}$ & $\begin{array}{l}\text { Enfase na disponibilidade fabril em } \\
\text { detrimento das necessidades do } \\
\text { mercado. }\end{array}$ \\
\hline
\end{tabular}

Fonte: Elaborado pelos autores 
Como se observa no Quadro 6, o conhecimento também se faz fundamental como input para a prática da aplicação da GD. É através dele que o nível estratégico pode se flexibilizar a fim de oportunizar subsídios e incentivos para que a corporação seja estimulada para uma cultura inovativa mediada pelo design. Já os inputs do nível tático estão diretamente relacionados aos do estratégico, pois o esclarecimento da estratégia pode facilitar as entradas necessárias para o nível tático: apoio administrativo (abertura nas tomadas de decisões); recursos financeiros (para poder investir em equipes qualificadas e pesquisas); processuais (processos organizacionais compatíveis com as intenções) e intelectuais (para contratar equipe qualificada e com tamanho necessário).

Todos estes fatores, quando exercidos de forma satisfatória, podem acarretar uma mediação fluída entre estratégia e operação (output). Por fim, os inputs do nível operacional podem ser facilitados pelos recursos gerenciais e tecnológicos. Os recursos gerenciais, por exemplo, podem ser facilitados por sistemas de gestão de projetos bem alinhados com o nível tático; e os recursos tecnológicos podem ser melhor geridos pela compreensão dos níveis estratégico (aporte financeiro) e tático (direcionamento financeiro).

Quadro 6: Inputs e outputs dos níveis de Gestão do Design

\begin{tabular}{|l|l|l|}
\hline & Inputs para a Gestão do Design & Outputs para a Gestão do Design \\
\hline $\begin{array}{l}\text { Nível } \\
\text { estratégico }\end{array}$ & $\begin{array}{l}\text { Conhecimento sobre as relações } \\
\text { entre design e negócios. }\end{array}$ & $\begin{array}{l}\text { Subsídio, incentivo e estruturação } \\
\text { financeira para apoiar o fomento à } \\
\text { cultura inovativa. }\end{array}$ \\
\hline Nível tático & $\begin{array}{l}\text { Apoio administrativo, recursos } \\
\text { financeiros, processuais e } \\
\text { intelectuais. }\end{array}$ & $\begin{array}{l}\text { Mediação coerente do design entre } \\
\text { os níveis estratégico e operacional. }\end{array}$ \\
\hline $\begin{array}{l}\text { Nível } \\
\text { operacional }\end{array}$ & $\begin{array}{l}\text { Recursos gerenciais e } \\
\text { tecnológicos. }\end{array}$ & $\begin{array}{l}\text { Qualidade, eficiência, eficácia e } \\
\text { preço coerente. }\end{array}$ \\
\hline
\end{tabular}

Fonte: Elaborado pelos autores

Contudo, pode-se observar que o fato de os inputs e outputs estarem correlacionados entre si, pode se colocar como um fator crítico na aplicação da GD, uma vez que, para ela ser implementada de forma bem-sucedida, é recomendável que todas as partes da empresa estejam sintonizadas com o mesmo objetivo e, acima de tudo, com os mesmos modelos mentais.

\section{Discussão dos resultados da pesquisa-ação}

Ao refletir acerca das atividades desenvolvidas nas empresas, percebeuse que, antes de implementar ações com vistas para a Gestão do Design nas companhias, se faz necessário realizar um processo de reconhecimento introdutório para identificar os fatores humanos e processuais presentes nelas (Figura 2).

Essa etapa consiste em, primeiramente, realizar um diagnóstico de reconhecimento (1) em diferentes áreas e cargos a fim de identificar (2) como os conceitos de design são compreendidos, relacionados e, sobretudo, exercidos. Acredita-se que os resultados podem colaborar para um conhecimento mais aprofundado das empresas estudadas, ajudar na análise dos seus FCS e evidenciar os fatores humanos e processuais envolvidos em cada companhia. Além disso, a compreensão das relações (3) existentes entre os FCS identificados e os níveis de GD (estratégico, tático e operacional) pode fomentar as ações necessárias (4) para a condução das práticas à luz da GD. 
Figura 2: Etapas do processo de aplicação da GD

Fonte: Elaborado pelos autores

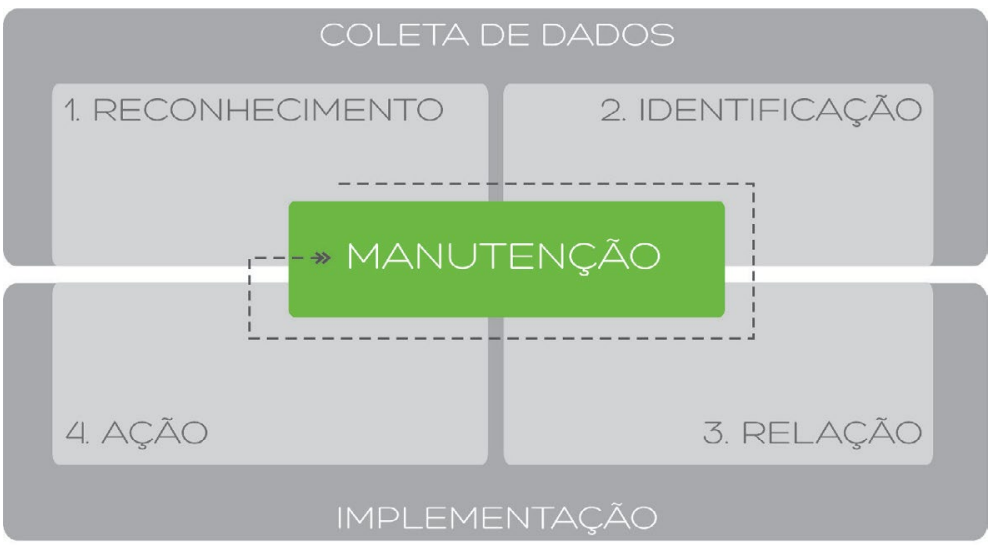

Todo esse processo está relacionado a diferentes papéis que os colaboradores das companhias possuem e que, consequentemente, impactam nos níveis estratégico, tático e operacional. Em todas as discussões realizadas, define-se que cada nível pode ser caracterizado por um verbo de ação que, como resultado, pode provocar um impacto organizacional específico. Mesmo que sintetizações possam beirar a superficialidade, estimam-se que os verbos que mais bem definem os três níveis são: "pretender/estimular" (estratégico); "entender/ articular/estruturar "(tático) e "fazer/testar/comunicar” (operacional) (Figura

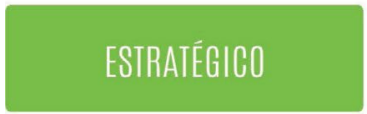

\section{TÁIICO}

\section{OPERACIONAL}

Figura 3: Insights da pesquisa-ação

Fonte: Elaborado pelos autores

\section{VERBO DE AĢÃO}

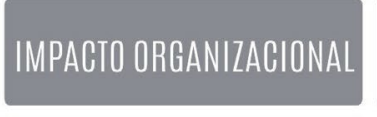

\section{PRÉ-REQUISITO}

Pretender, Estimular

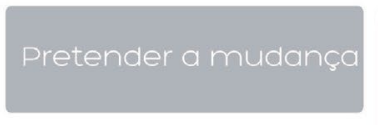

\section{Entender, Articula Estruturar}

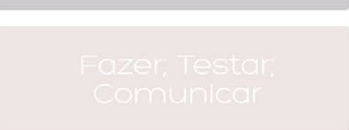

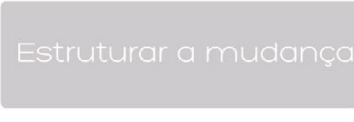

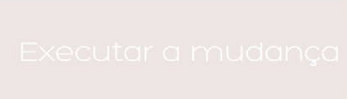

Estímulo ao gerenciamento das

competências e

da intenção de mudança

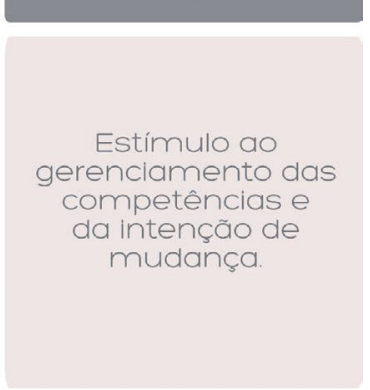

Com relação aos impactos organizacionais, estima-se que o estratégico deve pretender a mudança da empresa através da GD, enquanto o tático deve estruturá-la para que o operacional a execute. Para todos eles, acredita-se que o estímulo ao gerenciamento das competências (sejam individuais, coletivas ou organizacionais) e às intenções de mudanças mediadas pelo design são atividades caracterizadas como pré-requisitos para a aplicabilidade bem-sucedida da GD.

\section{CONSIDERAÇÕES FINAIS}

Ao analisar as discussões realizadas nos embasamentos teórico (revisão bibliográfica) e prático (pesquisa-ação) que fundamentaram este artigo, é possível observar que as competências correlacionadas com o design, sobretudo dos altos gestores, colocam-se como espinha dorsal no processo de gerenciamento da GD. Além disso, as análises também permitiram identificar características de importantes colaboradores que estão inseridos neste processo (principais atores e vetores) que, assim como os CEO, podem interferir na corporação de forma positiva ou negativa.

A percepção de que a empresa é uma engrenagem que deve partilhar objetivos idênticos em todos os níveis da organização é outra reflexão importante para a aplicação da GD em uma empresa, uma vez que corrobora 
a ideia de que, mesmo que em diferentes graus e envolvimentos, toda a corporação deve possuir a mesma intenção. Dessa forma, analisa-se que a ação de homogeneização de conhecimentos e expectativas pode se colocar como base estrutural para o desenvolvimento de práticas integradas do design em diferentes esferas.

Além disso, no caso de grandes empresas que já possuem culturas organizacionais desfavoráveis para a prática integrada do design, acreditase que a engrenagem corporativa possa ser mais facilmente deslocada se houver movimentos coerentes entre a pretensão, a estruturação e a execução da mudança.

Contudo, observou-se que as empresas possuem perfis corporativos distintos por diferentes motivos. Assim, tal constatação deve ser levada em conta para inserir a GD nas organizações. Assim, qualquer ferramenta que se intencione a realizar uma integração do design nas corporações deve possuir formas e mecanismos para flexibilizar seu uso de acordo com os diferentes perfis corporativos e os fatores humanos e processuais existentes.

\section{REFERÊNCIAS}

BERNARDES, M.; OLIVEIRA, G.; VAN DER LINDEN, J. ICD Project: in pursuit of guidelines to increase competitiveness in the Brazilian industry through innovative product Design management. Journal of Modern Project Management, Trois-Rivières, v. 2, n. 3, p. 62-75, 2015.

BEST, K. Design management: managing Design strategy, process and implementation. Switzerland: AVA, 2006.

BORJA DE MOZOTA, B. Design management: using Design to build value and corporate innovation. New York: Allworth, 2003.

BRUCE, M.; COOPER, R.; VAZQUEZ, D. Effective Design management for small businesses. Design Studies, Amsterdam, v. 20, n. 3, p. 297-315, 1999

CABRAL, G. G. Gestão de Design em indústrias de produtos de uso: um estudo de caso na Companhia Industrial de Vidros (CIV). 2008. 168 f. Dissertação (Mestrado em Design) - Programa de Pós-Graduação em Design, Universidade Federal de Pernambuco, Recife, 2008.

DUMAS, Â.; MINTZBERG, H. Managing Design: Designing Management. Design Management Journal, Hoboken, v. 1, n. 1, p. 36-46, 1989

GIMENO, J. M. I. Diseño e innovación: la gestión del diseño en la empresa. Madrid: McGraw Hill, 2000.

GIRARDI, P.; ROBIN, W. Analysis of collaboration for Project management. Computers in Industry, Amsterdam, v. 57, n. 8, p. 817-826, 2006.

GORB, P. Design management. New York: Van Nostrand Reinhold, 1990.
GORB, P.; DUMAS, Â. M. P. Silent Design. Design Studies, Amsterdam, v. 8, n. 3, p. 150-156, jul. 1987.

HALES, C. Analysis of the engineering Design process in an industrial context. Cambridge: Cambridge University, 1987.

JOHNSON, M. P.; McHATTIE, L. Making Design Explicit in Organisational Change: Detour or Latour. In: ACADEMIC DESIGN MANAGEMENT CONFERENCE: Design Management in an Era of Disruption, 19., 2014, London. Proceedings... Boston: Design Management Institute, 2014. p. 880-900.

JOZIASSE, F. Corporate strategy: bringing Design management into the fold. In: LOCKWOOD, T.; WALTON, T. (Eds.). Building Design strategy: using Design to achieve key business objectives. New York: Allworth, 2008.

KOOTSTRA, G. The incorporation of Design Management in Today's Business Practices: an analysis of Design management practices in Europe. Rotterdam: Design Management Europe, 2009.

KUMAR, V. 101 Design Methods: a structured approach for driving innovation in your organization. New Jersey: John Wiley \& Sons, 2012.

LIBÂNIO, C. Competências na formação e integração de indivíduos e equipes na Gestão do Design: um framework para a indústria do vestuário. 2014. 167 f. Tese (Doutorado em Engenharia da Produção) Universidade Federal do Rio Grande do Sul, Porto Alegre, 2014.

LIBÂNIO, C.; AMARAL, F. Aspectos da gestão de Design abordados em dissertações e teses no brasil: uma revisão sistemática. Revista Produção Online, Florianópolis, v. 11, n. 2, p. 565-594, jun. 2011. 
LIEDTKA, J.; ROSEN, R.; WILTBANK, R. The catalyst: how you can become an extraordinary growth leader. New York: Crown Business, 2009.

MARTINS, R. F. de F. A gestão de Design como uma estratégia organizacional: um modelo de integração do Design em organizações. 2004. 202 f. Tese (Doutorado em Engenharia da Produção) - Centro Tecnológico, Universidade Federal de Santa Catarina, Florianópolis, 2004.

MINUZZI, R.; PEREIRA, A.; MERINO, E. A. D. Teoria e Prática na Gestão do Design. In: CONGRESSO INTERNACIONAL DE PESQUISA EM DESIGN, 2., 2003, Rio de Janeiro. Anais... Rio de Janeiro: Anped, 2003.

PHILLIPS, P. L. Creating the perfect design brief: how to manage design for strategic advantage. 2. ed. New York: Allworth, 2012.
POWELL, E. Developing a framework for Design Management. Design Management Journal, Boston, v. 9, n. 3, p. 9-13, 1998.

TEIXEIRA, J.; SCHOENARDIE, R.; MERINO E. A. D. Design Management: management levels and project development relations. In: ACADEMIC DESIGN MANAGEMENT CONFERENCE: Design Management in an Era of Disruption, 16., 2011, Hong Kong. Proceedings... Boston: Design Management Institute, 2011. p. 194-201.

VOM STAMM, B. Managing innovation: Design and creativity. 2. ed. New Jersey: John Wiley \& Sons, 2008.

WALTON, T. Design Management as a business and academic discipline. Design Management Journal, Boston, v. 1, p. 5-7, 2000.

WOLFF, F. Sistemática de avaliação da gestão de Design em empresas. 2010. 233 f. Tese (Doutorado em Engenharia da Produção) - Universidade Federal do Rio Grande do Sul, Porto Alegre, 2010.
Bruna Ruschel Moreira brunaruschel18@gmail.com

Maurício Moreira e Silva Bernades bernardes@ufrgs.br

Rita Assoreira Almendra almendra@fa.ulisboa.pt 